$12,13,18$

\title{
Влияние подложки из оксида кремния на электронные свойства и электропроводность моно- и бислойных пленок из одностенных углеродных нанотрубок типа кресло: квантово-механическое исследование
}

\author{
(C) О.Е. Глухова, А.А. Петрунин
}

Саратовский национальный исследовательский государственный университет им. Н.Г. Чернышевского, Саратов, Россия

E-mail: glukhovaoe@info.sgu.ru

Поступила в Редакцию 18 мая 2021 г.

В окончательной редакции 30 мая 2021 г.

Принята к публикации 30 мая 2021 г.

Исследованы электрические свойства моно- и бислойных пленок из одностенных углеродных нанотрубок (ОУНТ), расположенных на подложках оксида кремния $\mathrm{SO}_{2}$. В качестве подложки - пленка кристалла диоксида кремния, характеризующая пространственной группой $\mathrm{P} 4_{2} / \mathrm{mnm}$ с поверхностью (100). В качестве ОУНТ рассмотрены трубки типа кресло субнанометрового диаметра $(4,4)$ и нанометрового диаметра $(7,7)$. Установлено, что диаметр нанотрубок во многом определяет электронные свойства пленки на подложке. Тонкие трубки $(4,4)$, сформированные в бислойную пленку (с взаимно перпендикулярной ориентацией друг относительно друга), обладают наименьшим сопротивлением. Подложка практически не оказывает влияния на электронные свойства подобной пленки. Пленки с трубками бо́льшего диаметра характеризуются бо́льшим значением сопротивления. Установлено, что решающее значение играет поверхность контакта ОУНТ - подложка.

Ключевые слова: электрическая проводимость, углеродные нанотрубки, оксид кремния, тонкие пленки, электронная зонная структура.

DOI: $10.21883 /$ FTT.2021.10.51421.119

\section{1. Введение}

Исследованию одностенных и многостенных углеродных нанотрубок (МУНТ) посвящено множество работ [1-36] в современной физике наноструктур, что объясняется их весьма выдающимися физическими свойствами. Особо стоит отметить термическую стабильность одностенных углеродных нанотрубок с теплопроводностью порядка $3 \mathrm{~kW} /(\mathrm{m} \cdot \mathrm{K})$ [1] и высокий показатель плотности тока автоэлектронной эмиссии, достигающие при комнатной температуре значения в $0.1 \mathrm{~A} / \mathrm{cm}^{2}[2-5]$. Одностенные углеродные нанотрубки (ОУНТ) характеризуются различным типом электрической проводимости в зависимости от их хиральности, выступая проводниками и полупроводниками с шириной запрещенной зоны в диапазоне $0.01-0.7 \mathrm{eV}$ [6]. Помимо всего прочего углеродные нанотрубки (УНТ) обладают весьма малой плотностью $\sim 1.3 \mathrm{~g} / \mathrm{cm}^{3}[7,8]$.

При этом современные исследователи не ограничиваются рассмотрением исключительно нанотрубок, как самостоятельного материала, но посредством введения различных добавок и объединения нескольких нанотрубок в сложные молекулярные комплексы, добиваются улучшения качеств материала по сравнению с „чистыми“ нанотрубками. К таким сложным соединениям стоит отнести: колонный графен [9-14], Х- и Ү-образные соединения [15-17] и композиты, в которых используется
УНТ [18]. Также имеет смысл усилить физические качества УНТ, поместив их на подложки разнообразных химических соединений.

Сообщается [19], что гибридное соединение $\mathrm{MnO}_{2}$ УНТ-графен, выращенное на подложке никеля $\mathrm{Ni}$, может найти применения в контактах суперконденсаторов, такое становится возможным благодаря высоким показателям проводимости $117 \mathrm{~S} / \mathrm{cm}$. В работе [20] в качестве подложки и диэлектрического слоя при создании гибкого транзистора используется поливиниловый спирт. Исследователи Зенг (Zheng) и др. выращивали многостенные углеродные нанотрубки на подложке тантала, а затем функционализировали их додецилсульфатом натрия для определения дофамина в присутствии аскорбиновой кислоты [21].

Из всего множества подложек особый интерес вызывает соединение оксида кремния $\mathrm{SiO}_{2}$, широко применяемого при производстве электронных устройств и в частности углеродных наноустройств [22-28]. Так, например, подложка оксида кремния $\mathrm{SiO}_{2}$ играет важную роль при проектировании транзисторов на основе слоев ОУНТ и МУНТ [22-28]. Несмотря на множество работ посвященных УНТ на подложках $\mathrm{SiO}_{2}$, некоторые вопросы недостаточно освещены. Стоит отметить, что значительная часть исследований [22-33] опирается на эмпирический опыт, который не может позволить прояснить некоторые принципиальные физические характери- 
стики наноструктур, в частности влияние подложки на зонную структуру и электропроводность.

В настоящей работе in silico исследуются электронные свойства моно- и бислойных пленок из ОУНТ типа кресло, расположенных на подложке оксида кремния $\mathrm{SiO}_{2}$ - композитных 2D-структур ОУНT/SiO 2 . Рассмотрены ОУНТ $(\mathrm{m}, \mathrm{m})$ для $m=4$ и 7 , соответственно диаметром $\sim 5$ и $\sim 10 \AA$, т.е. трубки суб- и нанометрового диаметров. Выбор трубок кресло обусловлен, во-первых, металлическим типом проводимости [34,35] и, во-вторых, отсутствием хиральности. Нехиральная трубка позволяет достаточно легко согласовать вектор трансляции трубки с вектором трансляции подложки, что не реализуется для хиральных трубок. Металлический тип проводимости ОУНТ выбран намеренно, чтобы выяснить влияние подложки на электрическую проводимость.

\section{2. Методы и подходы исследования}

Для исследования электронных свойств, в частности зонной структуры, применялся метод SCC-DFTB (метод функционала плотности в приближении сильной связи с самосогласованием заряда) [36-38]. Этот метод очень хорошо зарекомендовал себя в исследованиях электронных свойств новых композитных материалов, включая углеродные композитные материалы [39]. Полная энергия системы в рамках этого подхода определяется выражением

$$
E_{t o t}=\sum_{i \mu \nu} c_{\mu}^{i} c_{\nu}^{i} H_{\mu \nu}^{0}+\frac{1}{2} \sum_{\alpha \beta} \gamma_{\alpha \beta} \Delta q_{\alpha} \Delta q_{\beta}+E_{r e p}+E_{d i s},
$$

где $c_{\mu}^{i}$ и $c_{v}^{i}$ - весовые коэффициенты при разложения по атомным орбиталям, $\Delta q_{a}$ и $\Delta q_{\beta}-$ флуктуации заряда на атомах $\alpha$ и $\beta$, соответственно, $\gamma_{\alpha \beta}-$ функция, экспоненциально убывающая с ростом расстояния между атомами $\alpha$ и $\beta, E_{\text {rep }}$ - терм, описывающий отталкивательное взаимодействие на малых расстояниях, $E_{d i s}-$ энергия ван-дер-ваальсовое взаимодействие трубок с подложкой. Ван-дер-ваальсовое взаимодействие моделировалось с применением универсального силового поля (UFF), которое поддерживает описание взаимодействия различных атомов вплоть до $Z=103$ [40]. Применялся полный sp-базис и для разбиения первой зоны Бриллюэна - схема Монкхорста-Пака $12 \times 12 \times 1$ [41]. Поиск равновесной атомной конфигурации суперъячейки пленка-подложка проводился минимизацией полной энергии системы (1).

В исследованиях электропроводности был применен формализм Ландауэра-Буттикера [42], который определяет величину тока, протекающего через данную структуру, как функцию коэффициента пропускания $T(E)$. Таким образом, электрическая проводимость материала рассчитывалась по формуле

$$
G=\frac{1}{V}=\frac{e^{2}}{h} \int_{-\infty}^{\infty} T(E) F_{T}(E-\mu) d E
$$

где $F_{T}$ определяется выражением

$$
\begin{gathered}
F_{T}=\frac{1}{4 k_{B} T} \sec h^{2}\left(\frac{E}{2 k_{B} T}\right), \\
T(E)=\frac{1}{N} \sum_{k=1}^{N} \operatorname{Tr}\left[\Gamma_{s}(E) G_{C}^{A}(E) \Gamma_{D}(E) G_{C}^{R}(E)\right],
\end{gathered}
$$

Здесь $T(E)$ - усредненная по $k$ функция пропускания электронов (или функция передачи проводящего канала); $F_{T}$ - функция теплового уширения, $G_{C}^{A}(E)$, $G_{C}^{R}(E)$ - матрицы Грина, описывающие контакт с электродами; $\Gamma_{s}(E), \Gamma_{D}(E)$ - матрицы уширения уровня для стока и истока [42].

\section{3. Результаты}

Нами исследовались два типа пленок ОУНТ: монослойные и бислойные. Трубки, как выше указано, были нехирального типа $(m, m)$ для $m=4$ и 7. Монослойные пленки представлялись слоем из ОУНТ с расстоянием между трубками $3.4 \AA$ в одном случае и $4.0 \AA$ - в другом случае, бислойные - двумя монослойными пленками с взаимно перпендикулярной ориентацией нанотрубок разных слоев. Расчеты проводились при температуре $300 \mathrm{~K}$. Отметим, что для построения суперьячейки 2D-модели „пленка ОУНТ + подложка“ необходимо, чтобы трансляционный шаг периодической ячейки ОУНТ совпадал полностью с трансляционным шагом подложки в этом же направлении. Для трубок $(4,4)$ и $(7,7)$ это условие построения суперъячейки 2D-модели обеспечивается применением только одной топологической модели диоксида кремния - структуры с пространственной группой $\mathrm{P} 4_{2} / \mathrm{mnm}$ (https://materialsproject.org/materials/mp-6947). Топология поверхности выбрана в соответствие с известными экспериментальными данными о широко применяемых подложках для ОУНТ - топология (100). Толщина слоя подложки была выбрана равной $21.2 \AA$, то есть равной трем элементарным ячейкам по оси $Z$. Такой толщины слоя подложки вполне достаточно для исследования ее влияния на электронные свойства ОУНТ. На рис. 1, $a$ показаны суперъячейки монослойных пленок. В результате поиска равновесных конфигураций суперьячеек были определены векторы трансляций $L_{x}, L_{y}$, вдоль осей $\mathrm{X}$ и Y соответственно. В табл. 1 представлены векторы трансляций $L_{x}, L_{y}$ всех рассматриваемых моделей пленок на подложке.

Как известно, диоксид кремния является диэлектриком с большой запрещенной энергетической зоной $5.5 \mathrm{eV}$. В нашем случае речь идет о тонкой пленке 


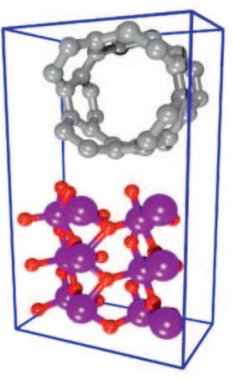

$(4,4)$

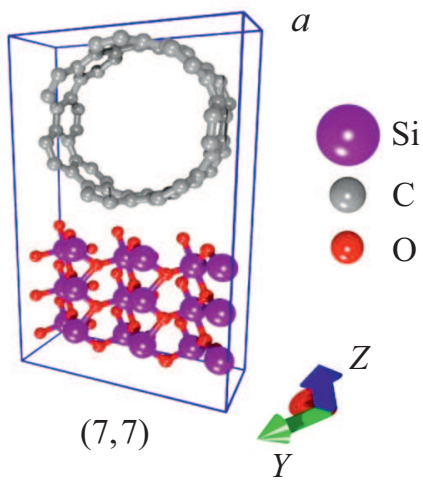

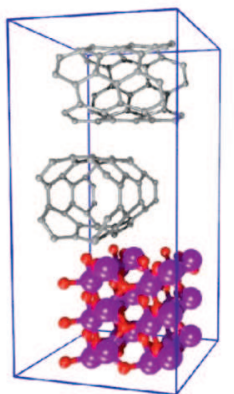

$(4,4)$

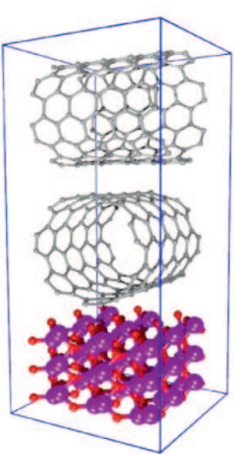

$(7,7)$ $b$

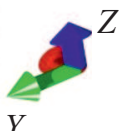

Y

Рис. 1. Атомистические модели моно- и бислойных пленок с шагом дистанцирования ОУНТ-ОУНТ равным 3.4 А̊: $a, b)$ суперъячейки монослойных и бислойных пленок на подложке оксида кремния.

Таблица 1. Метрические и энергетические параметры моно-/бислойных пленок

\begin{tabular}{|c|c|c|c|c|c|c|c|c|}
\hline Parameters & $L_{x}, \AA$ & $L_{y}, \AA$ & $E_{\text {gap }}, \mathrm{eV}$ & $E_{\mathrm{F}}, \mathrm{eV}$ & $L_{x}, \AA$ & $L_{y}, \AA$ & $E_{\text {gap }}, \mathrm{eV}$ & $E_{\mathrm{F}}, \mathrm{eV}$ \\
\hline \multicolumn{9}{|c|}{ Monolayer } \\
\hline Model & \multicolumn{4}{|c|}{ distance CNT-CNT $=3.4 \AA$} & \multicolumn{4}{|c|}{ distance CNT-CNT $=4.0 \AA$} \\
\hline$(4,4)$ & 8.82 & 4.92 & 0 & -5.62 & 9.42 & 4.92 & 0 & -5.63 \\
\hline$(7,7)$ & 12.9 & 4.92 & 0 & -4.6 & 13.49 & 4.92 & 0 & -4.69 \\
\hline \multicolumn{9}{|c|}{ Bilayer } \\
\hline Model & \multicolumn{4}{|c|}{ distance $\mathrm{CNT}-\mathrm{CNT}=3.4 \AA$} & \multicolumn{4}{|c|}{ distance CNT-CNT $=4.0 \AA$} \\
\hline$(4,4)$ & 8.82 & 8.82 & 0 & -4.87 & 9.42 & 9.42 & 0 & -5.99 \\
\hline$(7,7)$ & 12.9 & 12.9 & 0 & -5.06 & 13.49 & 13.49 & 0 & -4.66 \\
\hline
\end{tabular}

диоксида кремния, в связи с чем энергетические характеристики заметно меняются, и энергетическая щель составляет всего $3.9 \mathrm{eV}$. Для понимания природы и механизма формирования электронной структуры композитной 2D-структуры ОУНT/SiO 2 рассчитаны DOS для пленки подложки, отдельной ОУНТ и композитной 2D-структуры. На рис. 2 представлены графики DOS для случая дистанцирования ОУНТ-ОУНТ с шагом $3.4 \AA$ А. Рис. 2, $a, b, c$ - для монослойных пленок, рис. $2, d, e, f$ - для бислойных. Суперъячейки пленок из ОУНТ и суперъячейки подложки были взяты непосредственно из суперячейки соответствующей структуры ОУНТ + подложка.

Ширина щели $E_{g a p}$ и уровень Ферми $E_{\mathrm{F}}$ представлены в табл. 1, где указаны эти значения для двух случаев шага ОУНТ-ОУНТ $3.4 \AA$ и $4.0 \AA$. Прежде всего, хорошо видно, что большинство пиков интенсивности обусловлено пиками соответствующих профилей DOS пленок из нанотрубок, поскольку вблизи уровня Ферми DOS подложки имеет широкую запрещенную зону. Двухслойная пленка на подложке имеет заметно бо́льшую интенсивность DOS и бо́льшее количество пиков интенсивности вблизи уровня Ферми. Диаметр
ОУНТ в случае однослойной пленки не играет заметной роли, поскольку вблизи уровня Ферми значение DOS у них практически одинаково. Однако в случае бислойной пленки интенсивность на уровне Ферми заметно больше у пленки с тонкими трубками $(4,4)$. Надо отметить, что межтрубное расстояние сильно влияет на положение уровня Ферми, сдвигая его в сторону уменьшения, в большинстве случаев.

Для всех построенных моделей пленок из ОУНТ на подложках были рассчитаны функции пропускания и электропроводность. Как известно, трубки типа кресло имеют два канала проводимости на уровне Ферми [35] (канал проводимости отвечает одному кванту проводимости). Важным моментом является выяснение степени и характера влияния подложки диоксида кремния на проводимость пленки ОУНТ. На рис. 3 показаны графики функции пропускания монослойных пленок с шагом ОУНТ-ОУНТ 3.4 А̊и $4.0 \AA$. Направление выбрано вдоль осей трубок (направление $\mathrm{Y}-$ рис. 1). Значения указаны в квантах проводимости $\left(e^{2} / h, e-\right.$ заряд электрона, $h$ - постоянная Планка). Тонкие трубки $(4,4)$ субнанометрового диаметра сохранили свою высокую проводимость, как видно на рис. $3, a, b$, на уровне 

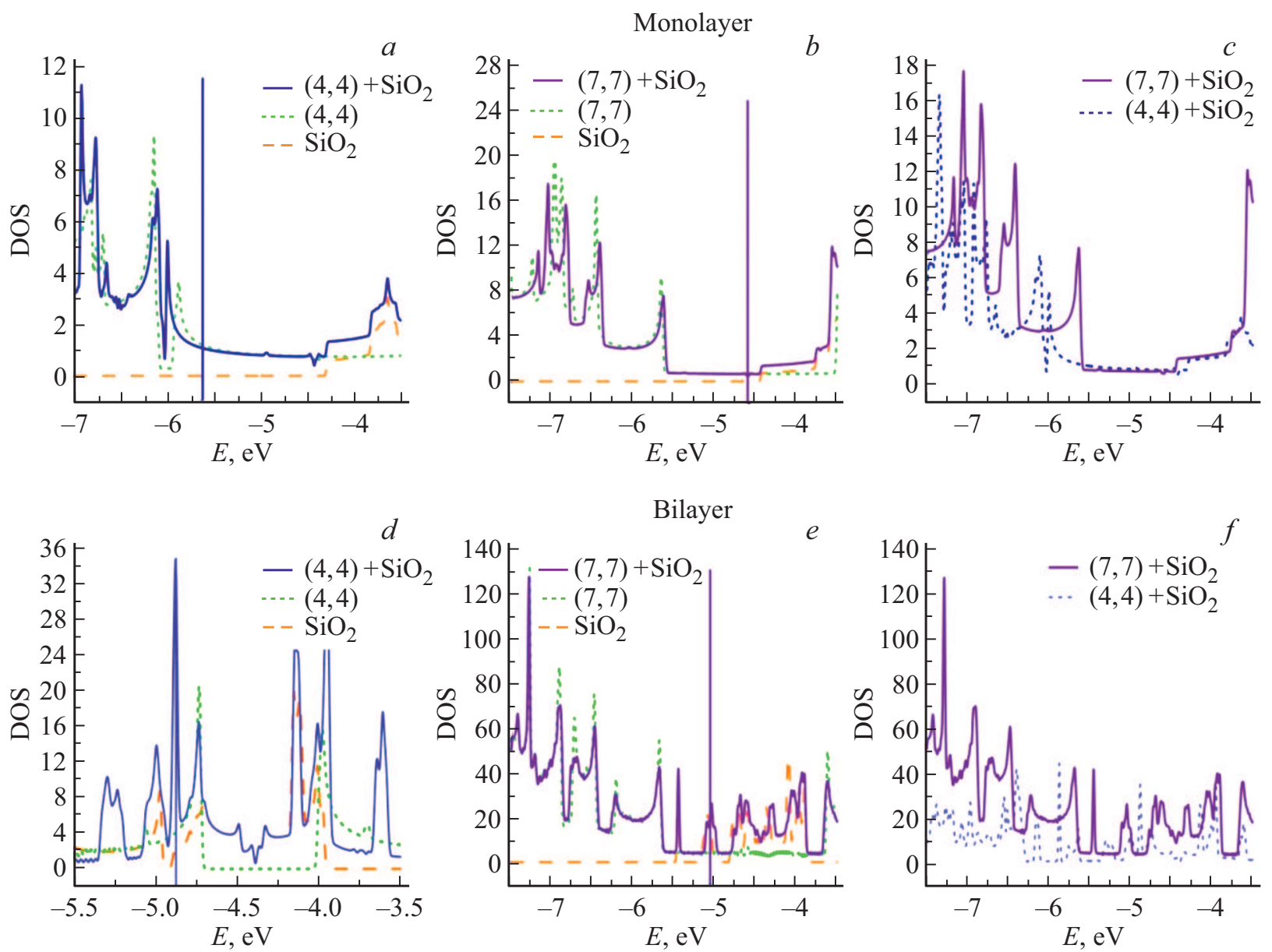

Рис. 2. Плотности электронных состояний монослойных пленок $(a-c)$ и бислойных $(d-f)$. Вертикальные прямые соответствуют уровню Ферми.

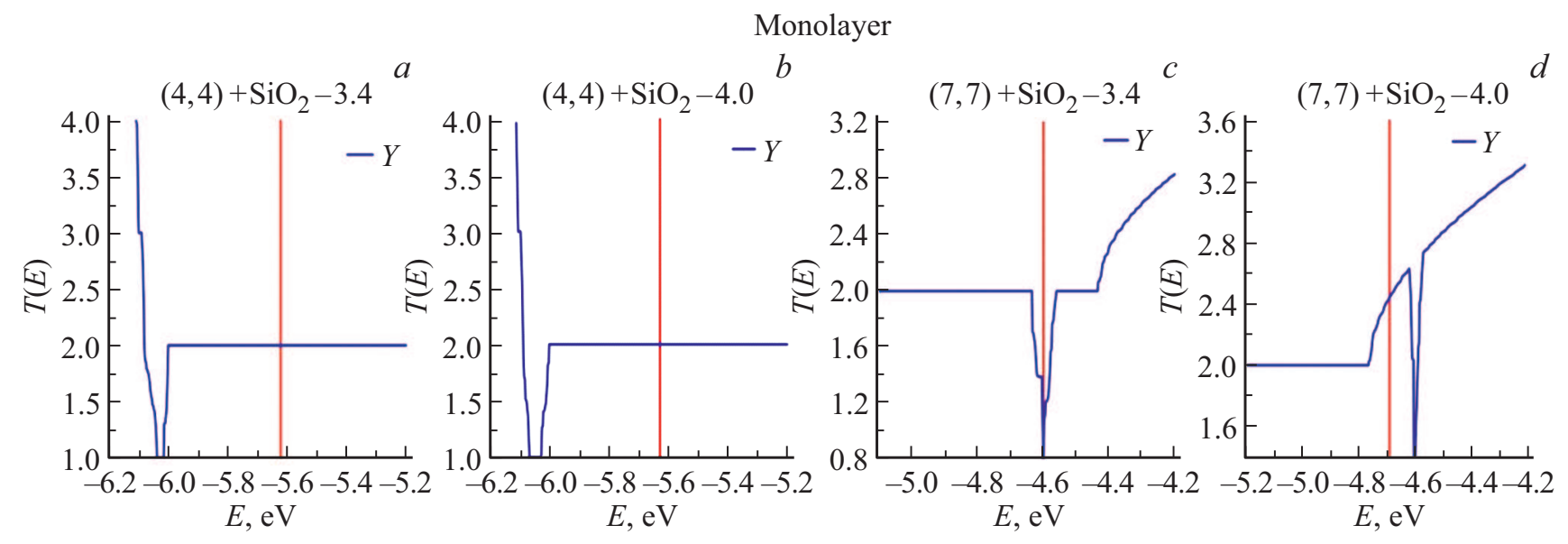

Рис. 3. Функции пропускания монослойных пленок с ОУНТ $(4,4)(a-b)$ и с ОУНТ $(7,7)(c-d)$. Красная вертикальная прямая соответствует уровню Ферми.

Ферми имеется два канала проводимости. Каждый канал проводимости (или квант) отвечает электропроводности $77.48 \mu \mathrm{S}$. Можно видеть, что расстояние между трубками мало влияет на профиль функции пропускания этих пленок. Однако, увеличение диаметра трубки заметно меняет профиль $T(E)$. Пленки с трубками $(7,7)$ демонстрируют уменьшение функции пропускания на уровне Ферми (рис. 3,c) при межтрубном расстоянии $3.4 \AA$. При увеличении расстояния между трубками до этот „провал“ в профиле функции сдвигается вправо, то 


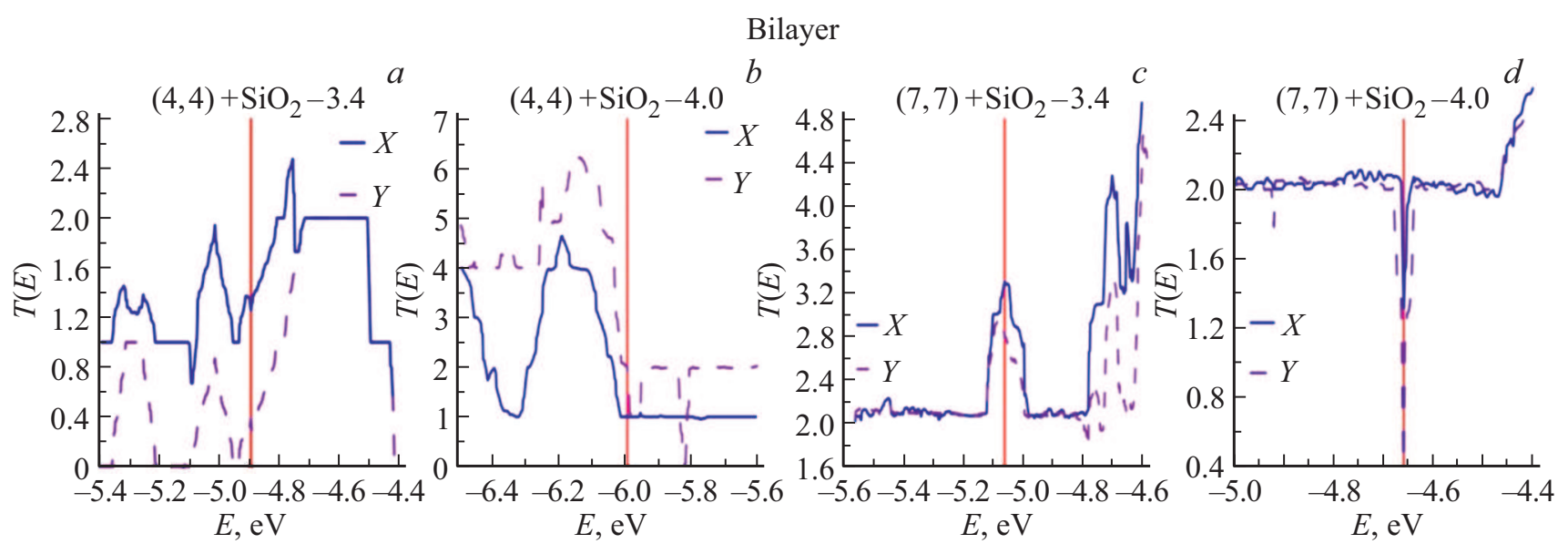

Рис. 4. Функции пропускания бислойных с ОУНТ $(4,4)(a-b)$ и с ОУНТ $(7,7)(c-d)$. Красная вертикальная прямая соответствуют уровню Ферми.

Таблица 2. Электрофизические параметры нанотрубных пленок на подложке

\begin{tabular}{|c|c|c|c|c|c|c|c|c|}
\hline Parameters & $R_{x}, \mathrm{k} \Omega$ & $R_{y}, \mathrm{k} \Omega$ & $\sigma_{x}, \mu \mathrm{S}$ & $\sigma_{y}, \mu \mathrm{S}$ & $R_{x}, \mathrm{k} \Omega$ & $R_{y}, \mathrm{k} \Omega$ & $\sigma_{x}, \mu \mathrm{S}$ & $\sigma_{y}, \mu \mathrm{S}$ \\
\hline \multicolumn{9}{|c|}{ Monolayer } \\
\hline Model & \multicolumn{4}{|c|}{ distance CNT-CNT $=3.4 \AA$} & \multicolumn{4}{|c|}{ distance CNT-CNT $=4.0 \AA$} \\
\hline$(4,4)$ & $\infty$ & 6.52 & 0 & 153.28 & $\infty$ & 6.52 & 0 & 153.28 \\
\hline$(7,7)$ & $\infty$ & 7.92 & 0 & 126.23 & $\infty$ & 5.45 & 0 & 182.84 \\
\hline \multicolumn{9}{|c|}{ Bilayer } \\
\hline Model & \multicolumn{4}{|c|}{ distance CNT-CNT $=3.4 \AA$} & \multicolumn{4}{|c|}{ distance CNT-CNT $=4.0 \AA$} \\
\hline$(4,4)$ & 9.34 & 33.74 & 107.06 & 29.63 & 8.37 & 4.76 & 119.41 & 209.95 \\
\hline$(7,7)$ & 4.55 & 5.01 & 219.92 & 199.96 & 6.54 & 7.42 & 152.97 & 134.72 \\
\hline
\end{tabular}

есть приходится на зону проводимости, а на уровне Ферми значение $T(E)$ становится больше двух, достигая значения 2.4. Появление „провала“ при расстоянии $3.4 \AA$ А, по сравнению с тонкой трубкой $(4,4)$, может быть объяснено увеличением контактирующей поверхности трубки с подложкой. Действительно, глядя на рис. 1, $a$, можно заметить, что тонкая трубка $(4,4)$ контактирует с подложкой всего лишь одним гексагоном, а трубка $(7,7)$ - тремя гексагонами. Увеличение контактной поверхности приводит к повышению влияния подложки на электронную структуру пленки, что и дает „провал“ на уровне Ферми. С увеличением межтрубного расстояния этот эффект влияния подложки нивелируется (рис. $3, d$ ).

Графики рассчитанных функций пропускания для бислойных пленок представлены на рис. 4. В отличие от монослойных пленок, в данном случае есть два направления токопереноса, поэтому представлены два графика при токопереносе вдоль направления Y (как и ранее для монослойного варианта), и вдоль направления $\mathrm{X}$ (для второго слоя трубок, см. рис. 1,c). Сравнивая два направления токопереноса, можно сразу увидеть, что в бислойных пленках выделяется именно направление X, то есть направление токопереноса второго слоя нанотрубок, несвязанного с подложкой. Именно это направление обнаружило повышенную электропроводность. Исключение составляет только случай пленки на основе $(4,4)$ при расстоянии $4 \AA$, когда проводимости практически совпадают в обоих направлениях. Для пленок на основе ОУНТ $(4,4)$ видно, что функция $T(E)$ на уровне Ферми уменьшилась до 0.4 в случае межтрубного расстояния $3.4 \AA$, и до 1 в случае $4 \AA$. Это объясняется большим влиянием второго слоя трубок. В результате частичного перекрывания электронных облаков соседних слоев трубок происходит перераспределение плотности электронного заряда на трубках, что и приводит к уменьшению значений функции на уровне Ферми. Для пленок на основе ОУНТ $(7,7)$ функция пропускания в случае межтрубного расстояния также больше на уровне Ферми, как и в случае тонких пленок. И также наблюдается аномалия для межтрубного расстояния $4 \AA$, когда функция $T(E)$ обнаруживает уменьшение на уровне Ферми. Большая контактная поверхность трубки $(7,7)$ все-таки приводит к переносу заряда от трубок к подложке. 
На основании рассчитанных функций пропускания пленок на подложках вычислены значения электропроводности (2). В табл. 2 приведены значения электропроводности $\sigma_{x}$ и $\sigma_{y}$ при разных межтрубных расстояниях, а также значения сопротивлений.

Анализ данных табл. 2 показывает, что бислойные пленки из трубок типа кресло являются высоко проводящими. Подобные пленки обеспечивают высокую проводимость в двух взаимно перпендикулярных направлениях. Сопротивление в обоих направлениях не превышает $34 \mathrm{k} \Omega$ для пленок на основе ОУНТ $(4,4)$ и $7.5 \mathrm{k} \Omega$ для пленок на основе ОУНТ $(7,7)$. Электрическое сопротивление меняется при изменении межтрубного расстояния. Это изменение не одинаково для трубок разного диаметра. Для пленок с тонкими трубками $(4,4)$ расстояние вообще не играет роли в случае монослойной пленки, однако, сопротивление бислойной пленки уменьшается с увеличением межтрубного расстояния. Сопротивление пленки с ОУНТ $(7,7)$ ведет себя по-другому при увеличении межтрубного расстояния. Из данных табл. 2 можно видеть, что электрическое сопротивление монослойной пленки уменьшается, в бислойной - увеличивается. Как и упоминалось выше, различие в поведении пленок на основе $(4,4)$ и $(7,7)$ определяется различием в поверхности контакта с подложкой, а также трубок друг с другом.

\section{4. Заключение}

Исследованы электронные и электрофизические свойства пленок на основе ОУНТ типа кресло субнанометрового диаметра, расположенных на подложке диоксида кремния с пространственной группой $\mathrm{P} 4_{2} / \mathrm{mnm}$ с поверхностью (100). Исследования актуальны, поскольку позволяют ответить на вопрос о степени влияния подложки на проводимость пленок углеродных нанотрубок. Установлено, что диаметр нанотрубок играет определяющую роль в процессе токопереноса. Трубки субнанометрового диаметра, сформированные в бислойную пленку (с взаимно перпендикулярной ориентацией друг относительно друга) обладают наименьшим сопротивлением $\sim 5 \mathrm{k} \Omega$. Подложка практически не оказывает влияния на электронные свойства пленки. Пленки с трубками бо́льшего диаметра характеризуются бо́льшим значением сопротивления. Установлено, что решающее значение играет поверхность контакта ОУНТ-подложка.

\section{Финансирование работы}

Работа выполнена при поддержке Минобрнауки России в рамках выполнения государственного задания (проект № FSRR-2020-0004).

\section{Конфликт интересов}

Авторы заявляют, что у них нет конфликта интересов.

\section{Список литературы}

[1] A.V. Radhamani, H.C. Lau, S. Ramakrishna. Composites A 114, 170 (2018).

[2] W.A. de Heer, A. Chatelain, D. Ugarte. Science 270, 5239, 1179 (1995).

[3] A.G. Rinzler, J.H. Hafner, P. Nikolaev, P. Nordlander, D.T. Colbert, R.E. Smalley, L. Lou, S.G. Kim, D. Tománek. Science 269, 1550 (1995).

[4] L.A. Chernozatonskii, Yu.V. Gulyaev, Z.Ja. Kosakovskaja, N.I. Sinitsyn, G.V. Torgashov, Yu.F. Zakharchenko, E.A. Fedorov, V.P. Val'chuk. Chem. Phys. Lett. 233, 1-2, 63 (1995).

[5] С.В. Булярский, А.А. Дудин, А.В. Лакалин, А.П. Орлов, А.А. Павлов, Р.М. Рязанов, А.А. Шаманаев. ЖТФ 88, 6 , 920 (2018).

[6] А.В. Елецкий. УФН 167, 9, 946. (1997).

[7] A.R. Tamboli. Handbook of structural steel connection design and detail. McGraw Hill, N. Y. (1999). 570 p.

[8] M. O’Connell. Carbon nanotubes: properties and applications. Taylor \& Francis, Boca Raton (2006). 360 p.

[9] V.V. Shunaev, O.E. Glukhova. Materials 13, 5219. (2020).

[10] M.M. Slepchenkov, D.S. Shmygin, G. Zhang, O.E. Glukhova. Nanoscale 11, 35, 16414 (2019).

[11] S. Karimzadeh, B. Safaei, T.C. Jen. J. Heat. Mass. Transfer 172, 121145 (2021)

[12] C.U. Deniz, H. Mert, C. Baykasoglu. Comput.Mater. Sci. 186, 110023 (2021)

[13] А.А. Петрунин, О.Е. Глухова. Наноэлектроника, нанофотоника и нелинейная физика. Сб. трудов XIV Bcepoc. конф. молодых ученых. (2019). С. 342.

[14] О.Е. Глухова, А.А. Петрунин. Вопросы прикл. физики 27, 48 (2020).

[15] F.Y. Meng, S.Q. Shi, D.S. Xu, R. Yang. Phys. Rev. 70, 125418 (2004).

[16] G. Ingarao, R. Di Lorenzo, F. Micari. Comput. Struct. 87, 9-10, 591 (2009).

[17] R. Di Lorenzo, G. Ingarao, F. Chinesta. Int. J. Adv. Manufacturing Technology 44, 49 (2009).

[18] A. Esawi, K. Morsi, A. Sayed, M. Taher, S. Lanka. Comp. Sci. Technology 70, 16, 2237 (2010).

[19] G. Zhu, Z. He, J. Chen, J. Zhao, X. Feng, Y. Ma, Q. Fan, L.-H. Wang, W. Huang. Nanoscale 6, 1079 (2014).

[20] S. Aikawa, E. Einarsson, T. Thurakitseree, S. Chiashi, E. Nishikawa, S. Maruyama. Appl. Phys. Lett. 100, 6, (2012).

[21] D. Zheng, J.S. Ye, W.D. Zhang. Electroanalysis 20, 1818 (2008).

[22] E.S. Snow, J.P. Novak, P. Campbell, D. Park. Appl. Phys. Lett. 82, 13, 2145 (2003).

[23] H.E. Romero, N. Shen, P. Joshi, H.R. Gutierrez, S.A. Tadigadapa, J.O. Sofo, P.C. Eklund. ACS Nano 2, 10, 2037 (2008).

[24] V. Derycke, R. Martel, J. Appenzeller, Ph. Avouris. Appl. Phys. Lett. 80, 2773 (2002).

[25] A.D. Franklin, Z. Chen. Nature Nanotech. 5, 858 (2010).

[26] A.D. Franklin. Nature 498, 443 (2013).

[27] G. Gruner. Anal. Bioanalyt. Chem. 384, 322 (2006).

[28] P. Avouris, R. Martel, V. Derycke, J. Appenzelle. Physica B 323, 1-4, 6 (2002).

[29] F. Chicatun, J. Cho, S. Schaab, G. Brusatin, P. Colombo, J. Roether, A. Boccaccini. Adv. Appl. Ceram. 106, 4, 186 (2007). 
[30] Z. Fei, A. Rodin, G. Andreev, W. Bao, A. McLeod, M. Wagner, L. Zhang, Z. Zhao, M. Thiemens, G. Dominguez, M. Fogler, A. Castro Neto, J. Lau, F. Keilmann, D. Basov. Nature 487, 82. (2012).

[31] Z. Fei, G. Andreev, W. Bao, L. Zhang, A. McLeod, C. Wang, M. Stewart, Z. Zhao, G. Dominguez, M. Thiemens, M. Fogler, M. Tauber, A. Castro Neto, J. Lau, F. Keilmann, D. Basov. Nano Lett. 11, 4701 (2011).

[32] F. Schedin, E. Lidorikis, A. Lombardo, V.G. Kravets, A.K. Geim, A.N. Grigorenko, K.S. Novoselov, A.C. Ferrari. ACS Nano 4, 5617 (2010).

[33] Y.K. Koh, M.-H. Bae, D.G. Cahill, E. Pop. Nano Lett. 10, 11, 4363 (2010).

[34] J. Doh, S.I. Park, Q. Yang, N. Raghavan. Nanotechnology 30, 46, 465701 (2019).

[35] G. Dresselhaus, M.S. Dresselhaus, R. Saito. Physical properties of carbon nanotubes. World scientific. Singapore. (1998). $272 \mathrm{p}$.

[36] T. Frauenheim, G. Seifert, M. Elstner, T. Niehaus, C. Kohler, M. Amkreutz, M. Sternberg, Z. Hajnal, A. Di Carlo, S. Suhai. J. Phys. Condens. Matter. 14, 11, 3015 (2002).

[37] T. Frauenheim, G. Seifert, M. Elstner, Z. Hajnal, G. Jungnickel, D. Porezag, S. Suhai, R. Scholz. Phys. Status Solidi 217, 41 (2000).

[38] Q. Cui, M. Elstner, E. Kaxiras, T. Frauenheim, M. Karplus. J. Phys. Chem. 105, 569 (2001).

[39] M.M. Slepchenkov, D.S. Shmygin, G. Zhang, O.E. Glukhova. Carbon 165, 139 (2020).

[40] A.K. Rappe, C.J. Casewit, K.S. Colwell, W.A. Goddard III, W.M. Skiff. J. Am. Chem. Soc. 114, 10024 (1992).

[41] H.J. Monhorst, J.D. Pack. Phys Rev. 13, 5188 (1976).

[42] S. Datta. Quantum Transport: Atom to Transistor. Cambridge University Press, N.Y. (2005). 420 p.

Редактор Т.Н. Василевская 